\title{
LĖTINIS KOSULYS
}

\author{
Kristina Stravinskaite, doc. dr. Brigita Šitkauskienè, \\ prof. dr. Raimundas Sakalauskas \\ KMU Pulmonologijos ir imunologijos klinika
}

\begin{abstract}
REIKŠMINIAI ŽODŽIAI: lètinis kosulys, astma, GERL, rinitas.
SANTRAUKA. Lètiniu kosuliu laikomas kosulys, kuris užsitęsia ne trumpiau kaip aštuonias savaites. Lètiniu kosuliu skundžiasi nuo 3 iki 40 proc. gyventojų. Dažniausios lètinio kosulio priežastys yra astma, gastroezofaginio refliukso liga ir rinitas. Paciento, kuris skundžiasi lètiniu kosuliu, tyrimo tikslas - nustatyti kosuli sukèlusią priežasti. Lètinio kosulio priežasti pavyksta nustatyti 75-90 proc. atvejų. Pagrindinis lètinio kosulio gydymo principas - ji sukèlusios priežasties šalinimas. Tokio gydymo veiksmingumas yra 68-98 proc. Jei lètinio kosulio priežasties nustatyti nepavyksta arba etiologinis gydymas negalimas ar neveiksmingas, skiriama kosuli slopinančių vaistų.
\end{abstract}

Lètiniu kosuliu laikomas kosulys, kuris užsitęsia ne trumpiau kaip aštuonias savaites [1]. Tai vienas dažniausių ir labiausiai varginančių kvėpavimo sistemos simptomu [2]. Lètiniu kosuliu skundžiasi nuo 3 iki 40 proc. gyventojų [3, 4, 5]. Dèl šio negalavimo pacientai bene dažniausiai kreipiasi ị gydytoją (apie $30 \mathrm{mln}$. apsilankymu per metus JAV) [6].

$2001 \mathrm{~m}$. atlikus apklausą, kurioje dalyvavo 18277 asmenys nuo 20 iki 48 metų iš 16 Europos šalių, paaiškejjo, kad lètiniu kosuliu dažniau skundžiasi moterys bei antsvorio turintys asmenys. Nustatyta, kad asmenys, metę rūkyti ir surūkantys iki 20 cigarečiuc per dieną, kosuliu skundžiasi rečiau nei daug rūkantys (daugiau kaip 20 cigarečiuc per dieną) [7]. Tikslių duomenų apie lètinio kosulio paplitimą Lietuvoje nèra. KMU Pulmonologijos ir imunologijos klinikos mokslo darbuotojai atliko tyrimą penkiuose Lietuvos rajonuose ir nustatè, kad lètinis kosulys vargino 30 proc. rūkančių, 18 proc. metusių rūkyti ir 17 proc. nerūkančių asmenų [8].

Kosulys yra normalus apsauginis refleksas, padedantis iš kvėpavimo takų pašalinti bronchų sekretą bei svetimkūnius. Smarkiai kosint slègis krūtinès ląstoje pasiekia $300 \mathrm{~mm} \mathrm{Hg}$, sistolinio kraujo spaudimas $140 \mathrm{~mm} \mathrm{Hg}$, o oro srovès greitis gali būti iki $800 \mathrm{~km}$ per valandą (85 proc. garso greičio), sunaudojama nuo 1 iki 25 J energijos. Šie slègio, greičio ir energijos pokyčiai lètinio kosulio metu gali sukelti įvairiausių komplikacijų: kvėpavimo sistemos (pneumotoraksas, balso užkimimas, gerklų trauma), širdies ir kraujagyslių sistemos (hipotenzija, bradiaritmija, tachiartimija), centrinés nervu sistemos (sinkopé, galvos skausmas, ūminè cervikalinè radikuliopatija, insultas), virškinamojo trakto (gastoezofaginis refliuksas, anoreksija, vėmimas) lyties ir šlapimo organų (šlapimo nelaikymas), skeleto raumenų (tiesiojo pilvo raumens plyšimas, šonkaulių lūžimas, raumenu skausmas) ir kitas (sunkios ligos baimé, gyvensenos kitimas, gyvenimo kokybès pablogèjimas). Dažniausios kosulio komplikacijos yra nuovargis (57 proc.), nemiga (45 proc.), kaulu ir raumenų skausmas (45 proc.), balso užkimimas (43 proc.), gausus prakaitavimas (42 proc.), šlapimo nelaikymas (39 proc.) [6].

\section{ETIOLOGIJA}

Kosulį sukelia mechaninių ar cheminių kosulio receptorių dirginimas, o ju yra ne tik viršutiniuose ir apatiniuose kvèpavimo takuose, bet ir perikarde, stemplèje, skrandyje, diafragmoje, išoriniame ausies kanale, ausies būgnelyje [9]. Taigi lètinio kosulio priežastis gali būti ne tik kvejpavimo, bet ir kituc organų sistemų patologija.

Pagrindinès lètinio kosulio priežastys (apie 90 proc. visų) yra trys: astma, gastroezofaginio refliukso liga (GERL) ir rinitas [10, 11, 12, 13]. Kitos priežastys gali būti kvèpavimo taku (lètinė obstrukcinè plaučių liga, bronchektazès, eozinofilinis bronchitas, tracheobronchomaliacija, svetimkūnis), plaučiu intersticinès, infekcinès ligos (gripas, kokliušas, tuberkuliozè, pneumonija), plaučių vẻžys, širdies nepakankamumas, diafragmos, perikardo pažeidimas, vaistai (angiotenziną konvertuojančių fermentų inhibitoriai (AKFI), svetimkūnis (pvz., plaukas) ausyje, psichogeninès.

Lètinio kosulio priežastị, ịvairių tyrèjų duomenimis, pavyksta nustatyti 75-90 proc. atvejų [10, 14]. Kosulys, kurio priežastis nenustatoma, vadinamas idiopatiniu. Tikrasis lètinis idiopatinis kosulys labai retas ir dažnai klaidingai diagnozuojamas, nes nenustatoma už kvėpavimo sistemos ribų esanti, jị sukèlusi patologija [1].

\section{PACIENTO, KURIS SKUNDŽIASI LĖTINIU KOSULIU, TYRIMAS}

Paciento, kuris skundžiasi lètiniu kosuliu, tyrimo tikslas nustatyti kosulį sukèlusią priežastị. Svarbu išsiaiškinti kosuli lydinčius simptomus ir klinikinius požymius, ko- 
kius vaistus pacientas vartoja, ar buvo viršutiniu kvẻpavimo takų infekcija kosulio pradžioje, ar pacientas rūko. Krūtinès ląstos organų rentgenogramą rekomenduojama atlikti kiekvienam lètinio kosulio varginam pacientui. Jei pacientas nerūko, nevartoja AKFI, krūtinès ląstos organų rentgenogramoje nematyti pokyčių arba jie minimalūs, toliau atliekami tyrimai dažniausioms lètinio kosulio priežastims, t. y. astmai, GERL, rinitui, nustatyti. Nepatvirtinus nė vienos minėtos patologijos, atliekami papildomi tyrimai lètinio kosulio priežasčiai nustatyti: fibrobronchoskopija, krūtinès ląstos kompiuterinè tomografija, ausų, nosies, gerklès, širdies tyrimai [1].

\section{ASTMOS SUKELTAS LĖTINIS KOSULYS}

Astma - viena dažniausių nerūkančių asmenų lètinio kosulio priežasčiu (24-29 proc.) [10, 15]. Kartu su kosuliu paprastai būna kitų astmai būdingų simptomų (priepuolinis dusulys, švokštimas, cypimas krūtineje). Tačiau yra astmatikų, kuriems kosulys - vienintelis simptomas. Tokia astma vadinama kosulio astma (angl. cough variant astma). Šių pacientų objektyvaus ir plaučių funkcijos tyrimų duomenys būna normalūs, o diagnozę patvirtina teigiamas bronchu provokacinis inhaliacinis mėginys su metacholinu. Kosulio astma sergančių pacientų kosulio reflekso jautrumas kaspsaicinui būna didesnis nei „klasikinių“ astmatikų. Kosulio ir „klasikinès“ astmos gydymo principai nesiskiria [1]. Astma, kaip lètinio kosulio priežastis, patvirtinama tik tada, kai tinkamai gydant kosulys praeina [16].

Eozinofilinis bronchitas lemia apie 13 proc. visu kosulio atvejų. Jis pasireiškia lètiniu kosuliu ir skreplių eozinofilija (daugiau nei 3 proc.). Eozinofiliniam bronchitui, ne taip kaip astmai, nebūdingas padidejęs bronchų reaktyvumas metacholinui ir grịžtama bronchų obstrukcija. Diagnozę patvirtina bronchų gleivinès histologinis tyrimas, tačiau jis atliekamas retai. Eozinofilinio bronchito sukeltam kosuliui būdingas geras atsakas ị gydymą inhaliuojamaisiais gliukokortikosteroidais $[1,12]$.

\section{GERL IR LĖTINIS KOSULYS}

Kosuli sergant GERL sukelia keletas veiksnių, nuo kurių priklauso kartu su kosuliu pasireiškiantys gastroezofagino refliukso simptomai.

Stemplès viršutinès dalies receptorių dirginimas, kurị sukelia iš skrandžio patekęs turinys, lemia ezofagotracheobronchini kosulio refleksą. Šiuo atveju gastroezofaginio refliukso simptomų nepatiria $50-70$ proc. pacientų. Kosulys nevargina naktị, stipresnis būna ryte, kalbant, juokiantis, valgant.

Kosuli gali paskatinti ir skrandžio turinio aspiracija, sukelianti viršutinių kvėpavimo takų kosulio receptorių dirginimą. Šiuo atveju bus ne tik kosulys, bet ir balso užkimimas, gerklès graužimas, laringoskopuojant matomas užpakalinis balso klosčių uždegimas.

Kosuliui kilus dèl apatinių kvèpavimo takų kosulio receptorių dirginimo aspiruotu skrandžio turiniu, būna ryškūs ir gastroezofaginio refliukso, ir kvèpavimo (skrepliavimas, švokštimas, dusulys, kraujo atkosejjimas, krū- tinès skausmas ir kt.) simptomai [17].

Gydant GERL protonu siurblio inhibitoriais, dieta, kosulys per aštuonias savaites praeina $70-100$ proc. pacientuc [18].

\section{RINITO IR SINUSITO SUKELTAS LĖTINIS KOSULYS}

Manoma, kad kosulys gali prasidèti dèl ryklès ir gerklų kosulio receptorių dirginimo, kurị sukelia ị nosiaryklę nutekantis sekretas. Nutekẻjimo ị nosiaryklę sindromas gali būti sergant alerginiu, vazomotoriniu rinitu, virusine, bakterine liga, nosies polipais, prienosinių ančių uždegimu ir kt. Tokiais atvejais, be kosulio, paprastai juntamas kutenimas gerklëje, norisi atsikrenkšti. Apžiūrint matyti sekreto tekejjimas nosiarykle, paraudusi, panaši i „grindinic", ryklès gleivinè. Tačiau lètinị kosulị rinosinusitas gali sukelti ir nesant nutekejjimo ì nosiaryklę sindromo. Sindromas gali būti gydomas nosies praplovimais druskos tirpalu, nosies gliukokortikoidais, antihistamininiais vaistais bei dekongestantais [1].

\section{AKFI IR LE்TINIS KOSULYS}

Kosulys vargina apie 15 proc. AKFI vartotoju. Manoma, kad ji paskatina kvėpavimo takų c skaidulų dirginimas bradikininu, nes jo kiekis dèl AKFI poveikio padideja. Kosulys, parastai neproduktyvus, gali atsirasti po kelių valandų, savaičių ar ménesių nuo vaistų vartojimo pradžios, ji lydi dirginimas, kutenimas ar graužimas gerklèje. Kosulys nepriklauso nuo vaisto dozès, o vèl pradejus vartoti tą pati ar kitą AKFI jis atsinaujina. Svarbiausia gydant AKFI sukeltą kosulinutraukti vaisto vartojimą, o vietoj jo, jei reikia, skirti angiotenzino II receptoriu inhibitorių. Nutraukus AKFI vartojimą kosulys praeina per 1-4 dienas, rečiau per 4 savaites. AKFI sukelto kosulio diagnozè patvirtinama tik praejjus kosuliui po vaisto nutraukimo [19].

\section{POINFEKCINIS KOSULYS}

Poinfekcinis kosulys lemia 11-25 proc. lètinio kosulio atvejų. Po ūminès viršutinių kvėpavimo takų infekcinès ligos kosulys gali tęstis aštuonias ir daugiau savaičių. Manoma, kad ittakos kosuliui turi dèl buvusios infekcijos padidèjęs viršutinių ir apatinių kvèpavimo takų kosulio receptorių jautrumas, nutekejjimo ì nosiaryklę sindromas, padidejjęs kvėpavimo taku reaktyvumas [20, 21] Poinfekcinis kosulys dažniausias persirgus Mycoplasma pneumoniae, Chlamidia pneumoniae, Bordetella pertusis sukeliamomis ligomis [22]. Kokliušas nèra reta, bet paprastai nediagnozuojama paauglių ir suaugusiųjų poinfekcinio lètinio kosulio priežastis. Lètinio poinfekcinio kosulio diagnozè nustatoma tik paneigus kitas kosulio priežastis.

\section{LÉTINIO KOSULIO GYDYMAS}

Gydant lètini kosuli siekiama atkurti normalu kosulio refleksą. Pagrindinis lètinio kosulio gydymo principas - 
ji sukèlusios priežasties šalinimas. Tokio gydymo veiksmingumas yra 68-98 proc.

Jei lètinio kosulio priežasties nustatyti nepavyksta arba etiologinis gydymas negalimas ar neveiksmingas, skiriama kosuli slopinančių vaistų. Kosuli slopinantys vaistai yra centrinio ir periferinio poveikio. Jie retina kosulio dažnumą ir mažina intensyvumą. Centrinio poveikio grupès svarbiausi vaistai yra kodeinas ir dekstrometorfanas. Šiai grupei dar priklauso morfinas, hidrokodonas, baklofenas, okseladinas ir kiti. Centrinio poveikio vaistai apatinių kvejpavimo takų patologijos sukeliamą kosuli slopina geriau nei sukeliamą viršutinių. Pagrindinis centrinio poveikio kosulị slopinančių vaistuc šalutinis poveikis - slopinimas ir virškinamojo trakto simptomai. Toks poveikis nebūdingas okseladinui, kuris

\section{CHRONIC COUGH}

Kristina Stravinskaite, Brigita Sitkauskiene,

Raimundas Sakalauskas

Clinic of Pulmonology and Immunology

Kaunas University of Medicine

Key words: chronic cough, asthma, gasroesophagal reflux, rhinitis.

Summary. Chronic cough is defined as a cough of more than 8 weeks duration. Chronic cough is being reported by 3-40 percent of population. There are three common causes of chronic cough: asthma, gasroesophagal reflux and rhinitis. The task of investigation patients with chronic cough is to evaluate the cause of chronic cough. A cause is identified in 75-90 percent of patients with chronic cough. The treatment of chronic cough is aimed at the underling disorder. It is successful in 68-98 percent of cases. Antitussive agents are used if the cause of cough is failed to evaluate or etiological treatment is not available or not effective.

\section{LITERATŪRA}

1. Morice A.H et al. The diagnosis and managment of chronic cough. ERS task force // Eur Respir J 2004; 24: 481-492.

2. French $\mathrm{CT}$, Irwin RS, Fletcher KE, Adams TM. Evaluation of cough-specific quality of life questionnaire // Chest 2002; 121: 1123-1131.

3. Fuller RW, Jackson DM. Physiology and treatment of cough // Thorax 1990; 45: 425-430.

4. Loundon RG, Brown LC. Cough frequency in patients with respiratory disease // Am Rev Respir Dis 1967; 96: 1137-1143.

5. Cullinan P. Persistent cough and sputum: prevalence and clinical characteristics in south east England // Respir Med 1992; 86: $143-$ 149.

6. Irwin RS, Boulet LP, Cloutier MM, et al. Managing cough as a defense mechanism and as a symptom. A nonsensus panel report of the American College of Chest Physicians // Chest 1998; 114: Suppl. 2, 133S-181S

7. Janson C, Chinn S, Jarvis D, Burney P. Determinants of cough in young adults participating in the European Community Respiratory Health Survey // Eur Respir J 2001; 18: 647-654.

8. Malakauskas K, Sakalauskas R, Dudzevičius V, Žemaitis M, Staikūnienè ,Plieskiene $A$. Rúkymo paplitimo bei plauciu ventiliacijos rodmen selektyviai slopina kosulio centrą, nesukelia mieguistumo, neveikia virškinamojo trakto. Šalutinio slopinamojo poveikio nedaro periferinio poveikio kosuli slopinantys vaistai: benzonatas, guaifenesinas, levodropropizinas, moguisteinas, inhaliuojamieji anestetikai, teobrominas, GABA agonistai ir kt.

Deja nepakanka klinikinių tyrimų duomenų, irodančių vienos ar kitos grupés vaistų veiksmingumą slopinant kosulị. Daugelis naujai sukurtų vaistų veiksmingai slopina kosuli gyvūnams, bet jų poveikis žmonėms dar neįrodytas. Be to, atrasta keletas naujų kosulio mechanizmų, o juos žinant galbūt pavyks sukurti vaistus, slopinančius padidèjusị jutiminių skaidulų jautrumą ir veiksmingai gydančius kosulį [23, 24].

tyrimas tarp Lietuvos penkių rajonų suaugusių gyventojų // Medicina 2001; 9

9. Fontana A.G, Lavorini F. Cough motor mechanisms // Respiratory Physiology and Neurobiology 2006; 152 266-281.

10. Irwin RS, Curley FJ, French CL. Chronic cough. The spectrum and frequency of causes, key components of the diagnostic evaluation, and outcome of specific therapy // Am Rev Respir Dis 1990; 141:640-647.

11. Marchesani F, Cecarini L, Pela R, Sanguinetti CM. Sauses of chronic persistent cough in adult patients: the results of a systematic management protocol // Monaldi Arch Chest Dis 1998; 53: 510-514.

12. Brightling $C E$, Ward R, Goh KL, Wardlaw AJ, Pavord ID. Eosinophilic bronchitis is an important cause of chronic cough // Am J Respir Crit Care Med 1999; 160: 406-410.

13. Simpson G. Investigation and management of persistent dry cough // Thorax 1999; 54: 469-470.

14. Kastelik J. A, Aziz I, Ojoo J. C, Thompson R. H, Redington A. E, Morice A. H. Investigation and management of chronic cough using a probability-based algorithm // Eur Respir J 2005 25: 235-243

15. McGarvey LP, Heaney LG, Lawson JT, et al. Evaluation and outcome of patients with chronic non-productive cough using a comprehensive diagnostic protocol // Thorax 1998; 53:738-743

16. Irwin RS, French CT, Smyrnios NA, Curley FJ. Interpretation of positive results of a methacholine inhalation challenge and 1 week of inhaled bronchodilator use in diagnosing and treating cough-variant asthma // Arch Intern Med 1997; 157: 1981-1987.

17. Ing $A J$, Ngu MC, Breslin AB. Pathogenesis of chronic persistent cough associated with gastroesophageal reflux // Am J Respir Crit Care Med 1994; 149: 160-167.

18. Kiljander TO, Salomaa ER, Hietanen EK, Terho EO. Chronic cough and gastro-oesophageal reflux: a doubleblind placebo-controlled study with omeprazole. // Eur Respir J 2000; 16: 633-638.

19. Dykewicz MS. Cough and angioedema from angiotensin-converting enzime inhibitors: new insights into mechanisms and managment // Curr Opin Allergy Clin Immunol 2004; 4:267.

20. Curley FJ, Irwin RS, Pratter MR. Cough and common cold // Am Rev Respir Dis 1988; 138:305.

21. Hegele RG, Hayashi S, Hogg JC et al. Mechanisms of airway narrowing and hyperresponsiveness in viral repiratory tract infections. // Am J Respir Crit Care Med 1995; 142:832.

22. Strebel $P$, Nordin J, Edwards K, et al. Papulaton-based incidente of pertussis among adolescents and adults, Minnesota, 1996. // J Infect Dis 2001; 183:1353.

23. Bolser DC. Curent and future centrally-acting antitussive // Respiratory Physiology and Neurobiology 2006; 152 349-353.

24. Dicpinigaitis PV. Curent and future peripherally-acting antitussive // Respiratory Physiology and Neurobiology 2006; 152 356-359. 